\title{
CONTENTS OF PROCEEDINGS, VOLUMES I, III, IV, AND V
}

\section{Volume I-Statistics}

JOSEPH BERKSON, Estimation by least squares and by maximum likelihood. Z. W. BIRNBAUM, On the use of the Mann-Whitney statistic. HERMAN CHERNOFF and HERMAN RUBIN, The estimation of the location of a discontinuity in density. ARYEH DVORETZKY, On stochastic approximation. SYLVAIN EHRENFELD, Complete class theorems in experimental design. G. ELFVING, Selection of nonrepeatable observations for estimation. ULF GRENANDER and MURRAY ROSENBLATT, Some problems in estimating the spectrum of a time series. J. L. HODGES, JR. and E. L. LEHMANN, Two approximations to the Robbins-Monro process. WASSILY HOEFFDING, The role of assumptions in statistical decisions. SAMUEL KARLIN, Decision theory for P6lya type distributions. Case of two actions, I. L. LE CAM, On the asymptotic theory of estimation and testing hypotheses. HERBERT ROBBINS, An empirical Bayes approach to statistics. MURRAY ROSENBLATT, Some regression problems in time series analysis. CHARLES STEIN, Efficient nonparametric testing and estimation. CHARLES STEIN, Inadmissibility of the usual estimator for the mean of a multivariate normal distribution. B. L. VAN DER WAERDEN, The computation of the $X$-distribution.

\section{Volume III-Astronomy and Physics}

O. J. EGGEN, The relationship between the color and the luminosity of stars near the sun. J. L. GREENSTEIN, The spectra and other properties of stars lying below the normal main sequence. H. L. JOHNSON, Photoelectric studies of stellar magnitudes and colors. G. E. KRON, Evidence for sequences in the color-luminosity relationship for the M-dwarfs. G. C. McVITTIE, Galaxies, statistics and relativity. JERZY NEYMAN, ELIZABETH SCOTT and C. D. SHANE, Statistics of images of galaxies with particular reference to clustering. BENGT STRÖMGREN, The Hertzsprung-Russell diagram. F. ZWICKY, Statistics of clusters of galaxies.

ANDRE BLANC-LAPIERRE and ALBERT TORTRAT, Statistical mechanics and probability theory. M. KAC, Foundations of kinetic theory. J. KAMPE DE FERIET, Random solutions of partial differential equations. E. W. MONTROLL, Theory of the vibration of simple cubic lat tices with nearest neighbor interactions. NORBERT WIENER, Nonlinear prediction and dynamics.

\section{Volume IV-Biology and Problems of Health}

JAMES CROW and MOTOO KIMURA, Some genetic problems in natural populations. E. R. DEMPSTER, Some genetic problems in controlled populations. JERZY NEYMAN, THOMAS PARK and ELIZABETH SCOTT, Struggle for existence. The Tribolium Model: biological and statistical aspects.

M.S. BARTLETT, Deterministic and stochastic models for recurrent epidemics. A. T. BHARUCHAREID, On the stochastic theory of epidemics. C. L. CHIANG, J. L. HODGES, JR. and J. YERUSHALMY, Statistical problems in medical diagnoses. JEROME CORNFIELD, A statistical problem arising from retrospective studies. D. G. KENDALL, Deterministic and stochastic epidemics in closed populations. W. F. TAYLOR, Problems in contagion.

\section{Volume V-Econometrics, Industrial Research, and Psychometry}

K. J. ARROW and LEONID HURWICZ, Reduction of constrained maxima to saddle-point problems. E. W. BARANKIN, Toward an objectivistic theory of probability. C. W. CHURCHMAN, Problems of value measurement for a theory of induction and decisions. PATRICK SUPPES, The role of subjective probability and utility in decision-making.

A. H. BOWKER, Continuous sampling plans. CUTHBERT DANIEL, Fractional replication in industrial research. MILTON SOBEL, Sequential procedures for selecting the best exponential population.

T. W. ANDERSON and HERMAN RUBIN, Statistical inference in factor analysis. FREDERICK MOSTELLER, Stochastic learning models. HERBERT SOLOMON, Probability and statistics in psychometric research: Item analysis and classification techniques. 